\title{
Sağlık kurumlarında yeşil insan kaynakları yönetimi ve uygulamaları
}

\author{
Abdurrahman Yunus Sarıyıldız
}

aSamsun Üniversitesi, İktisadi, İdari ve Sosyal Bilimler Fakültesi, Sağlık Yönetimi Bölümü, yunus.sariyildiz@samsun.edu.tr ORCID NO: 0000-0003-2526-5016.

\author{
MAKALE BILGILERi \\ Araştırma Makalesi \\ Geliş Tarihi 21 Mart 2021 \\ Revizyon 20 Nisan 2021 \\ Revizyon 23 Nisan 2021 \\ Kabul tarihi 23 Nisan 2021
}

\begin{abstract}
Özet
Sağlık kurumları tarafından sunulan sağlık hizmetlerinin temel hedefi insan ve toplum sağlığının geliştirilmesidir. Bu hedef, dışsal fayda olarak insanın yaşam çevresine de çok yönlü katkı sağlamaktadır. Sağlıklı bireyler, sağlıklı toplum ve çevre için olumlu katkı sağlamaktadırlar. Sağlık kurumlarında üretilen ve sunulan hizmetin ana yürütücüsü ise sağlık personelidir. Her ne kadar çok yüksek teknoloji kullanılsa da sağıı hizmeti emek yoğun bir ortamda sunulmaktadır. Sağlık işgücünün verimli ve etkili hizmet sunumu, kurumun uyguladığı insan kaynakları politikaları ile doğrudan ilişkilidir. Son yıllarda yeni uygulama alanı bulan yeşil insan kaynakları politikaları sürdürülebilir yönetim için uygulanmakta ve geliştirilmektedir. Sağlık kurumları ise faaliyetleri gereği; atık yönetim sistemleri ile çevre ve insan sağlığına duyarlı, çevre yönetim sistemlerini geliştirmektedir. Sağlık kurumlarında çevre yönetim sisteminin yeşil insan kaynakları uygulamaları ile geliştirilmesi ve uygulanması, sağlık hizmetlerinin dışsal faydalarının daha belirgin olmasına sebebiyet verecektir. Nitekim yeşil insan kaynakları politikalarının amaçlarından birisi de dış paydaşlar için olumlu faydalar sunabilmektir. Sağıık personelinin istihdamından başlanmak üzere, yeşil hedefler ve duyarlılık ile kurumda çalışmasının sağlanması, insan kaynakları yönetiminin önemli bir başarısı olacaktır. Bu başarı sağılı kurumlarının olağanüstü durumlara da (salgın, afet, kriz vb.) uyumlaşmasını kolaylaştırabilecektir. Aynı zamanda geleneksel iKY uygulamaları ile beraber yeşil ikY uygulamalarının sağıı kurumları tarafından benimsenmesi, personelin motivasyonunu yükselterek, örgütsel sürdürülebilirliği sağlamaya yardımcı olabilecektir. Çevresel duyarlıık ve faaliyet ekseninde hizmet sunulması da sağlık kuruluşlarının toplumsal imajı ve yararlılı̆ı açısından son derece önemlidir. Bu çalışmada daha çok üretim işletmeleri tarafından benimsenmekte olan yeşil insan kaynakları politikalarının, sağlık kurumları tarafından uygulanabilirliği incelenmiştir. Aynı zamanda Türkçe yazına teorik bir çerçevede, yeşil insan kaynakları politikalarının sağlık kurumlarında uygulanabilirliği noktasında katkı sağlamak ve farkındalık oluşturmak amaçlanmıştır.
\end{abstract}

Anahtar Kelimeler: Sağlık Kurumları, İnsan Kaynakları Yönetimi, Yeşil iKY, Yeşil ikY Uygulamaları

\section{Green human resources management and practices in healthcare organizations}

\section{ARTICLE INFO}

Research Article

Received 21 March 2021

Received in revised form 20 April 2021

Received in revised form

23 April 2021

Accepted 23 April 2021

\section{Abstract}

The main goal of health services provided by healthcare organizations is to improve human and community health. These goals, as an external benefit, also contribute to the living environment of human in multiple ways. Healthy individuals make a positive contribution to a healthy society and environment. The main operator of the service produced and offered in healthcare organizations is health personnel. Although very high technology is used, health care is provided in a labor-intensive environment. The efficient and effective service delivery of the health workforce is directly related to the human resources policies implemented by the organization. Green human resources policies, which have found new application areas in recent years, are also implemented and developed for sustainable management. Healthcare organizations, as per their activities; It develops waste management systems and environmental management systems that are sensitive to the environment and human health. The development and implementation of the environmental management system in healthcare organizations with green human resources practices will cause the external benefits of health services to be more evident. As a matter of fact, one of the goals of green human resources policies is to provide positive benefits for external stakeholders. Starting with the employment of healthcare personnel, ensuring that they work in the organization with green goals and sensitivity will be an important success of human resources management. This success will make it easier for healthcare organizations to adapt to extraordinary situations (pandemic, disaster, crisis, etc.). At the same time, the adoption of green HRM practices along with traditional HRM practices by healthcare organizations may increase the motivation of the personnel and help to ensure organizational sustainability. Providing services on the axis of environmental awareness and activity is also extremely important for the social image and usefulness of healthcare organizations. In this study, the applicability of green human resources policies, which are mostly adopted by production companies, by healthcare organizations was examined. In addition, it is aimed to contribute to Turkish literature in a theoretical framework and to raise awareness about the applicability of green human resources policies in healthcare organizations.

Key Words: Healthcare Organizations, Human Resources Management, Green HRM, Green HRM Practices

\section{Giriş}

Küreselleşme ve artan rekabet koşulları, işletmelerin çevreye karşı daha duyarlı olmalarını ve faaliyetlerini çevresel hassasiyetleri göz önüne alarak sürdürmeleri noktasında baskı oluşturmaya devam etmektedir. Dolayısıyla çevresel sorunların çözümü ve yönetimi için, işletmeler yeşil yönetim ve uygulamalarını benimsemektedirler.

Bugün dünyamızda küresel olarak, çevre politikacıları ve araştırmacıları; kaynakların azalması, artan kirlilik ve biyolojik çeşitlilik kaybı gibi çevresel bozulmaların nedenlerinin insanın olumsuz davranışlarına dayandığı fikri üzerine yoğunlaşmaktadırlar. Bunun için birçok kurum ve kuruluş, günlük faaliyetlerin çevreye daha az zararlı olmasını sağlayabilmek adına, çevre yönetim sistemleri ve yeşil girişimlerin uygulanması yoluna gitmektedir (Anwar vd., 2020).

Yeşil insan kaynakları yönetimi (Yeşil IKY), hem çalışanlar hem de işletmeler için sürdürülebilir çevre yönetim stratejileri için yol gösterici olabilecektir. Yeşil IKY uygulamaları, çalışanların istenen çevresel performansa yönelik tutum ve davranışlarını etkilediği için organizasyonel değişimde önemli bir rol oynamaktadır. Literatürde yapılan bazı çalışmalarda; işe alma, eğitim ve ücretlendirme gibi bazı Yeşil ikY uygulamalarının, çalışanlar aracılığıyla sürdürülebilir hedeflere ulaşmak için güçlü araçlar olduğu ortaya konulmuştur (Jeronimo vd., 2020).

Kurumların çevresel konularda proaktif bir yaklaşım içerisinde olmaları, performanslarına da katkı sağlayabilecek yeşil insan kaynakları uygulamalarını hayata geçirebilmeleri için önemlidir (Oncer, 2019). İnsan kaynakları yönetiminin klasik uygulamaları, kuruluşun çevre hedefleriyle uyumlu hale getirilmesi şeklinde bir anlayış, Yeşil IKY uygulamaları ile örtüşmemektedir. Bu nedenle, çalışanların kuruluşların çevre bilincini geliştirme ve kuruluşların çevre dostu davranışlarını teşvik etme kararlarına dahil olması gerekir (Siyambalapitiya vd., 2018).

Yeşil insan kaynağı, her çalışanın karbon ayak izini azaltmak ve uygun yetenekleri elde tutmak için kullanılan bir strateji olarak belirtilmektedir. Çalışanlar, çevresel ve iklimsel değişim konusunda giderek daha fazla endişe duymaya başlamışlardır. Yeşil insan kaynakları, esas olarak prosedürler dâhilindeki yetkinliği 
artırmaya, çevresel israfı ortadan kaldırmaya, azaltmaya ve ayrıca daha yüksek yetkinlik sağlayan ve giderleri azaltan insan kaynakları uygulamalarını yeniden gözden geçirmeye odaklanmaktadır (Kumar, 2020).

İnsan kaynakları uygulamaları, kurumlar için sürdürülebilir iş stratejileri oluşturmada ve uygulamada stratejik bir rol oynayabilmektedir. Yeşil ikY de, çevresel sürdürülebilirliğin sağlanması için çevre yönetiminin insan kaynakları yönleri ile ilgilenmektedir. Bir başka ifade ile yeşil íkY, tipik insan kaynakları yönetimi uygulamalarının kuruluşların çevresel hedefleri ile sistemli ve planlı bir şekilde uyumlaştırılmasına yönelik çabaları içermektedir (Yu vd., 2020).

Yeşil IKY politika ve uygulamaları, son yıllarda özellikle başta üretim işletmeleri olmak üzere birçok kurum tarafından benimsenmiş ve uygulanmaktadır. Sağılık kurumları da hizmet üretim işletmeleri arasında önemli bir yer almaktadır. Sağılı kurumlarının sundukları hizmetin asli sonucu insan hayatı ile ilgilidir. İnsan sağlığı da aynı zamanda neticesi itibariyle sosyal, çevresel ve ekonomik sürdürülebilirlik ile ilişkilidir.

Çevre sağlığı ve sürdürülebilir yaşam kalitesi birçok farklı yönden etkileşim halindedir. Sağlıksız bir çevre aynı zamanda sağlıksız bir toplumun oluşmasına sebebiyet verebilecektir. Sağlık hizmetlerinin ana üreticisi ve sunucusu ise sağık kurumlarıdır. Sağlık kurumlarının faaliyetlerini sürdürürken çevreye duyarlı politikalar belirlemeleri, aslında insan sağlı̆ıına dolaylı katkı yapabileceği için, çevre ve insan sağlığı birbirini tamamlayan niteliktedir.

Sağlık kurumlarında uygulanan atık yönetim sistemleri ile çevreye duyarlı politikaların benimsendiği ve uygulandığı söylenebilmektedir. Ancak bu politikaların tüm kurum tarafından benimsenmesi ve uygulanması, insan kaynakları yönetiminin önemli görevleri arasında yer almalıdır. Sağılık personeline çevre bilinci kazandırmak adına yeşil iKY uygulamalarının, sağık kurumları tarafından daha sistemli hayata geçirilmesi, sağlık hizmetinin dışsal faydalarını daha artıracaktır.

Bu çalışmada; yeşil insan kaynakları uygulamalarının sağlık kurumlarında uygulanabilirliği ve fonksiyonları incelenmektedir. Önce sağlık kurumlarında insan kaynakları yönetimi (iKY) ve Yeşil iKY kavramlarından bahsedilecektir, daha sonra da yeşil iKY uygulamalarından; yeşil işe alım, yeşil eğitim ve geliştirme, yeşil performans yönetimi ve yeşil ücret yönetimi incelenip, değerlendirilecektir.

\section{Sağılık Kurumlarında İnsan Kaynakları Yönetimi}

İnsan kaynakları yönetimi, kurumların istenilen olumlu performansa ulaşabilmeleri için, tüm faaliyetlerini bir araya getiren ve bütünleştiren en önemli unsur olarak değerlendirilmektedir (Rawashdeh, 2018). Üst yönetim, kurumun performansını ileriye götürebilecek bir fonksiyon olarak insan kaynakları yönetimini benimsiyorsa, tehditlerin bertaraf edilip, sürdürülebilir gelişmeye olanak sağlayacak bir unsur olarak íKY, önemli bir rol oynayabilecektir (Mousa \& Othman, 2019).

Gelişen teknoloji ve küreselleşme ile beraber, kurumlar insan kaynağının öneminin farkına varmışlardır. İnsan kaynakları yönetimi kavramı da insan sermayesinin makul ve verimli kullanılması fikrinden doğmuştur. Bu yüzden işletmeler, faaliyetlerini yürütürken, sürdürülebilir rekabet avantajı ve yüksek performans elde etmek için insan kaynakları politikalarına ve uygulamalarına daha fazla önem vermeye başlamışır (Vardarlıer, 2016).

İnsan kaynakları yönetimi, bir organizasyonun en değerli varlıkları olan insan gücü ile ilgilenen önemli bir yönetim sürecidir. Bu bağlamda iKY, kurumların her alanında sürdürülebilirlik üzerine yoğunlaşmalıdır (Ahmad, 2015).

Son zamanlarda kurumlar, gerekli şartlar ve koşullarda rekabet ederek, varlıklarını koruyabilmek için çevresel konularda daha duyarlı ve verimli olabilmek adına çevreci uygulamalara yönelmektedirler. Bu bağlamda kuruluşlar hem çevreye verilen zararları en aza indirmek hem de kendi sürdürülebilirliğini artırmak yolunda faaliyetler gerçekleştirmektedirler (Demir Uslu \& Kedikli, 2017). Bu faaliyetlerin kurum içinde uygulanabilmesi için insan kaynakları yönetiminin önemli bir role sahip olduğu belirtilebilir. Çünkü bu uygulama ve faaliyetler, bir vizyon ve misyon uyumlaştırmasından daha çok, kurum kültürü olarak çalışanların hem iş hem de sosyal hayatlarında yansımaları olabilecek davranışlar olarak algılanmalıdır.

Hizmet işletmelerinden olan sağık kurumları, her ne kadar gelişmiş teknik ekipmanlar kullansa da emek yoğun bir teknolojiye sahiptirler. Sağlık hizmetlerinin ertelenemez, acil ve yaşamsal özelliği, hizmeti üreten insan gücünün niteliği ve rolünün önemini ortaya koymaktadır. Çünkü sağılık kurumlarında tüm faaliyetler birçok kademe ve görevdeki personelin eş zamanlı ve uyum içerisinde çalışması ile mümkün olmaktadır. Sağlık işgücünün verimli hizmet sunumu için sağlık kurumlarında insan kaynakları yönetimi ve uygulamalarının gelişmesi katkı sağlamaktadır (Kavuncubaşı \& Yıldırım, 2018).

Sağlık kurumlarında çalışan personelin kurumlarından beklentilerini karşılayabilecek şekilde tasarlanmış insan kaynakları yönetimi ve uygulamalarının sağlanması son derece önemlidir (Korkmazyürek, 2019). Sağlık hizmetinin asıl üreticisi ve sunucusu konumunda olan sağlık personeli, beklentilerinin karşılandığı ve kendisini mutlu hissettiği bir kurumda, verimli ve etkili hizmet sunabilecektir. Dolayısıyla IKY uygulamalarının çalışan beklenti ve isteklerine uygun olarak belirlenmesi ve hayata geçirilmesi gerekmektedir.

\section{Sağlık Kurumlarında Yeşil İnsan Kaynakları Yönetimi}

İnsan kaynakları yönetimi ve uygulamaları, kurumların birimlerinde ve bütününde fiilen uygulanan aktivitelerdir. Aynı şekilde, yeşil ikY uygulamaları da kurumlarda fiilen gerçekleşen programlar ve süreçlerdir. Yeşil ikY uygulamaları, kurumun olumsuz çevresel etkilerini azaltarak, olumlu etkilerini artırmayı amaçlayan politikalardır. Dolayısıyla yeşil IKY uygulamalarının nihai amacı, kurumun sürdürülebilir çevresel performansının iyileştirilmesi olarak belirtilebilir (Arulrajah vd., 2015).

Çevresel performansın iyileştirilmesinde insan kaynakları yönetiminin rolü doksanlı yılların ortalarından itibaren daha hissedilir ölçüde olmaya başlamıştır. Çevrenin iyileştirilmesi süreci kademe kademe ilerlemeye devam etmektedir. Yeşil yönetim girişimlerinin kurumlarda uygulanabilmesi için birçok iKY uygulaması, yeşil yönetim anlayışının yaygınlaştııılmasında yardımcı olmaktadır (Zaid vd., 2018).

2008 yılına kadar, insan kaynakları ve çevre yönetimi entegrasyonu tam olarak isimlendirilememiştir. Yeşil ikY, Renwick ve arkadaşları (2008) tarafından yapılan bir araştırma ile insan kaynakları yönetiminin gündemine sistematik bir şekilde dâhil olmaya başlamıştır. Böylece insan kaynakları bilim adamları çevresel konulara odaklanma çabası içerisine girmişlerdir. Daha sonraları yeşil insan kaynakları yönetimi terimi kullanılmaya başlanmışır (Renwick vd., 2008; Jabbour \& Jabbour, 2016). Literatürde yeşil insan kaynakları yönetimi terimi kullanılmaya başlandıktan sonra çeşitli tanımlamalar yapılmıştır. Yeşil insan kaynakları politikaları, bireylerin, toplumun ve çevrenin yararı için kurumlar tarafından uygulanan politikalar ve sistemler olarak tanımlanabilir (Cabral vd., 2019).

Yeşil IKY, kuruluşun ekolojik yönetim hedeflerinin insan kaynakları süreçlerine dahil edilmesini, yani işe alma ve seçme, eğitim ve geliştirme, performans yönetimi ve değerlendirme, ödüller ve takdiri kapsamaktadır (Singh vd., 2020). Ayrıca Yeşil insan kaynakları yönetimi; kuruma bağlılı̆̆ı ve iş performansı yüksek çalışanlar için insan kaynakları uygulamalarını da kapsayabilmektedir. Ancak, yeşil ikY birkaç açıdan daha farklı bir yapıdadır. Bunlardan ilki, kurumların çevreyi koruma yönelimlerini ve ekonomik etkilerinin yanında ekosistemlere etkilerinin de olumlu yönde olabilmesi için çabaları içermektedir. íkinci olarak; kurumların iç yönetim süreçleri ve operasyonel performanslarının iyileştirilmesinin dışında, dış paydaşlar için daha doğrudan faydalı politikalar sunabilmesidir (Tang vd., 2018).

Yapılan bazı çalışmalarda, Yeşil iKY uygulamalarının, çalışanlar arasında kuruluşun çevresel sonuçlarını iyileştiren tutum ve davranış değişikliklerini teşvik ettiği belirtilmektedir. Ayrıca, çevresel sonuçlar ile firma performansı arasında pozitif bir ilişki olduğu da tespit edilmiştir (Garcia vd., 2021).

Hizmet işletmeleri arasında bulunan sağlık kurumlarının diğer sektörlere göre farkı bir yapısı bulunmaktadır. Sağlık kurumlarında sunulan sağlık hizmetlerinin en nihai sonucu insan ve insan hayatıyla ilgilidir. Sağlık hizmetlerinin başlıca özellikleri şu şekilde belirtilebilir; ertelenemez, ikamesi yoktur, hata ve belirsizliğe izin verilemez ve emek yoğundur (Zennun Beyatlı, 2017). Çevre yönetimi politikaları da insanın daha sürdürülebilir bir yaşam çevresinde hayatını devam ettirebilmesi için çaba göstermektedir. Hem sağlık hizmetinin hem de çevre yönetiminin uygulamalarının, sağlık kurumlarında personele daha etkili şekilde aktarabilmesi için yeşil íKY'nin hayata geçirilmesi önemli bir adım olacaktır.

Sağlık kurumları, sağık hizmeti sunumunda özellikle çevresel atık yönetimi olmak üzere, farklı konularda çevreye duyarlı faaliyetler gerçekleştirmektedir. Tedavi hizmetlerinde uygulanan yöntemlerin insan ve çevreye en az zararı verecek şeklide organize edilmesi, sağık kurumlarının önemli kalite göstergeleri arasında yer almaktadır. Bu hizmetlere ek olarak tüm kurum tarafından uygulanabilecek olan yeşil ikY politikalarının uygulanması ile sağlık kurumları, çevresel sorunlara daha duyarlı hale gelebilecektir.

Çalışmanın bu bölümünde, sağık kurumları açısından yeşil insan kaynakları uygulamalarından yeşil işe alım, yeşil eğitim ve geliştirme, yeşil performans yönetimi ve yeşil ücret yönetimi uygulamaları incelenecektir. 


\subsection{Yeşil İ̧̧e Alım}

Bir kuruma yön veren, onu başarıya ya da başarısızlığa götüren en önemli öğenin insan gücü olduğu yadsınamaz bir gerçektir. Kurumun ihtiyaçları doğrultusunda en uygun personeli seçmek ise insan kaynakları yönetiminin en zor ve hassas konularından birisidir (Sabuncuoğlu, 2013).

Kurumların işe alım politikalarını etkileyecek olan yeşil işe alım ve seçme süreci, araştırmacılar tarafından yeşil ikY uygulamalarından birisi olarak değerlendirilmekte ve önemi de her geçen gün artmaktadır. Yeşil işe alım, çevresel konulara duyarlı ve çevresel performansa bağı kalmaya istekli adayları işe alma ve seçme süreci olarak adlandırılmaktadır (Pham \& Paille, 2019).

Günümüzde iş arayan adaylar da kendilerine uyumlu hissettikleri kurumları daha çok tercih etmektedirler. Genel anlamda işe alım politikalarında yeşil insan kaynakları hassasiyetleri, yani çevresel itibar ve değerlerin iyi yönetilmesi, adayların değerlendirmelerinde etkili olmaya başlamıştır. Ayrıca işe alım faaliyetlerinin; gazete reklamı, broşürler gibi geleneksel medya yerine, web tabanlı olarak yürütülmeye başlaması ile kurumların adayların çevre yönetimine karşı duyarılıı̆ı hakkında daha fazla bilgi sahibi olabilmesine imkân tanımıştır (Renwick vd., 2013).

Yeşil politikalar uygulayarak yeşil bir kurum olmak isteyen kurumlar, çevreye karşı yeşil değerleri ve tutumları olan açık fikirli adayları tercih etmektedirler. Kuruluşlar ayrıca işe alım ekibine adaylarla paylaşmaları gereken, kurumun yeşil politikalarını da öğretmelidirler (Al Kerdawy, 2019).

Kurumlar işe alım yaparken çevresel yetkinliklere sahip bireyleri işe alarak aynı zamanda kendi imajlarına da katkı sağlamaktadırlar (Yavuz, 2020). Yeşil işe alma, çevrenin önemine odaklanılan ve onu organizasyon içinde önemli bir unsur haline getiren bir sistemdir (Ahmad, 2015).

Sağlık kurumları, yüksek teknoloji kullanan, sürekli değişim ve gelişim içerisinde olan bir yapıdadır. Bu teknolojiyi kullanacak olan sağlık işgücünün istihdamı etkili olamazsa, asıl üretim olan sağlık hizmet sunumunda yetersizlikler ortaya çıkacaktır (Bektaş, 2011). Sağlık kurumlarında personel işe alınırken gerekli yetkinliklerin yanında, yeşil politika ve uygulamalara da duyarlı ve hedefleri olan işgücünün seçilmesi, yeşil íKY uygulamalarının başında gelmektedir.

\subsection{Yeşil Eğitim ve Geliştirme}

Yeşil IKY uygulamalarından bir tanesi de yeşil eğitim ve geliştirme faaliyetleridir. Yeşil uygulamalara geçiş ve bu anlayışın çalışanlar tarafından tam olarak benimsenebilmesi, sürekli eğitim ve geliştirme faaliyetleri ile sağlanabilecektir. Bu değişim için yeşil politikaların, çalışanlara eğitim yoluyla hissettirilip, uygulanmasının sağlanması gerekmektedir (Yavuz, 2020).

Kurumların eğitim ve geliştirme faaliyetlerinde Yeşil ikY uygulamalarını dikkate alması ve bu uygulamaları çalışanlarına benimsetmek için gerekli eğitim faaliyetlerini hayata geçirmeleri, yeşil eğitim ve geliştirmenin amaçlarından birisidir. Ayrıca yeşil faaliyetlerin başarılı bir şekilde organizasyonun stratejik hedeflerine entegre edilmesinde çalışanın rolü ve sorumluluğu dikkate alınmalıdır (Millar vd., 2016).

Yeşil eğitim ve geliştirme; çalışanların çevresel konulardaki farkındalığını ve bilgisini artırmayı, olumlu bir tutum geliştirmeyi, çevresel kaygılara karşı proaktif bir yaklaşım benimsemeyi ve enerjiyi korumak ve atıkları azaltmak için yetkinlikler geliştirmeyi amaçlar. Çevre eğitimi, insan kaynakları uygulamalarının en önemli alanlarından biri olarak belirtilebilmektedir (Mishra, 2017).

Çalışanların yetenekleri geliştirilirken, onlara çevresel duyarlılık veren eğitim programları uygulanabilir. Nitekim yapılan çalışmalar göstermiştir ki, bir bütün olarak çalışanların yetenekleri, 'yeşil' yetkinlik oluşturma uygulamaları ile artırıldığında, çalışanlar çevresel faaliyetlere daha fazla istekli olarak katkı sağlamaktadırlar (Pinzone vd., 2016).

Sağlık kurumlarında, hizmet üretim ve sunumunda personelin belirleyici bir rolü bulunmaktadır. Çünkü bir sağlık personelinin başarısı veya başarısızlığı doğrudan insan hayatı ile ilgili telafisi mümkün olmayan bir sonuca etki edebilir. Bu çerçevede sağıı insan kaynaklarının sürekli geliştirilmesi ve eğitim süreçlerine dâhil edilmesi, istenmeyen sonuçların azaltılmasına katkı sağlayacaktır. Ayrıca, sağlık kurumlarında verilen hizmetin kalitesini belirleyen en önemli unsurlardan bir tanesi sağlık personelidir (Kavuncubaşı \& Yıldırım, 2018).

Sağlık personelinin değişen hasta ve hasta yakını beklentilerine karşı sürekli eğitim ve geliştirme süreci içerisinde olması, verilen hizmetin kalitesine olumlu katkı sağlayacaktır. Yeşil ikY uygulamaları da yeşil eğitim süreçleri içerisinde personele aktarılarak, personelin bu duyarlılı̆a sahip olabilmesi hedeflenmelidir.

\subsection{Yeşil Performans Yönetimi}

Performans yönetim sistemi, bir çalışanın verimliliğini analiz eden, eksik yönlerini bulmaya çalışan ve bu konularda geleceğe yönelik hedefler belirleyen bir süreçtir. Bu nedenle, bir çalışanın çevreye karşı tutum, davranışlarının geliştirilmesi ve iyileştirilmesi için yeşil performans yönetim sistemi uygulamalarından yararlanmak, kurumlar için sürdürülebilirlik açısından önemli bir aşamadır (Mishra, 2017).

Yeşil performans yönetimi uygulamaları, çalışanların davranışlarını kuruluşun çevre hedefleriyle uyumlu hale getirmeyi amaçlamaktadır. Kuruluşlar performans yönetim sistemlerine çevresel faaliyetleri dâhil ettikleri zaman, çalışanların kurum-çevre uyumu için daha fazla önermede bulunduğu belirtilmektedir. Bu tespit yeşil performans yönetimi sisteminin, kurumun sürdürülebilir hedefleri için önemli bir katkı sağladığını göstermektedir (Pinzone vd., 2016).

Temel performans değerlendirme sistemlerine, yeşil hedefler dahil edilerek, yeşil performans yönetim sistemi anlayışı geliştirilebilir. Bu sistemin içerinde tüm kademelerdeki çalışanlar için, yeşil performans standartları ve yeşil davranış göstergeleri eklenebilir. Aynı şekilde yöneticiler için yeşil hedefler belirlenerek, bu hedeflere yöneticilerin ulaşmadaki başarısı, performans değerlendirmelerine dahil edilebilir. Astlar için de bu tür hedeflere ulaşmadaki katkıları, yeşil konulardaki farkındalıkları ve bu faaliyetlere katılmaları yönünde, performans değerlendirme standartları geliştirilebilir (Deshwal, 2015).

Yeşil performans yönetimi, çevresel kaygılar ve kuruluşun politikaları ile ilgili konulardan oluşur. Aynı zamanda çevresel sorumluluk konusuna da odaklanır (Ahmad, 2015). Yeşil performans yönetimi uygulamaları, duygusal bağlılık gibi içsel motivasyonu etkilemenin yanı sıra dışsal motivasyonu da etkileyen bir güç olabilecektir (Pinzone vd., 2016).

Sağlık kurumları açısından stratejik önemde olan amaçlara ulaşmada, sağlık personelinin başarı değerlendirmesi ve performans yönetiminin etkili uygulanması önemli role sahiptir (Kavuncubaşı \& Yıldırım, 2018). Geleneksel başarı değerlendirmelerine ek olarak yeşil hedeflerin değerlendirilmesi, yeşil IKY'nin kurumun çevre yönetimi stratejisine katkısını artıracaktır.

\subsection{Yeşil Ücret Yönetimi}

Çalışanlar için hayatlarını devam ettirebilmek adına kurumlarından aldıkları ücret önemli bir iş gayesidir. Hem çalışanlar hem de kurumlar için faydalı olması beklenen anlayış, duyarlı bir ücret politikasının uygulanmasıdır. Ancak bu sayede etkili bir ücret yönetimi politikası uygulanmış olabilir (Bingöl, 2014).

Kurumların, çevresel hedeflerinin gerçekleştirilmesi sürecinde çalışanlarına yönelik verdiği her türlü ödüllendirme faaliyetlerine, yeşil ücret yönetimi faaliyetleri adı verilmektedir (Yavuz, 2020). Yeşil ödüllendirme ve takdir, esnek çalışma programları ve evden çalışma gibi yeşil ödüllerle birleştiğinde çalışan performansına katkıda bulunabilmektedir (Amrutha \& Geetha, 2020).

Maaş, terfi ve kademe yükseltilmesinde olduğu gibi çalışanların yeşil ücret yönetimi sadece temel faaliyetlerle sınırlı kalmamalıdır. Aynı zamanda yeşil ödül ve takdir mekanizmaları işletilmelidir. Bu çerçevede, çevresel hedeflere ulaşan çalışanlar, başarılarından dolayı ödüllendirilmeli ve takdir edilmelidir (A Kerdawy, 2019). Ayrıca çalışanlar, çevre dostu bir kültür yaratma çabalarından dolayı ödüllendirilmelidir. Bu çabalar, iş yerinde yeşil davranışları teşvik etmek, yaşam tarzı ve karbon ayak izini azaltmak vb. olabilmektedir (Mishra, 2017).

Yeşil insan kaynakları yönetimi uygulamaları, organizasyonlarının yeşil değerlerini anlayan ve kurumsal sosyal sorumluluk gerekliliklerine uyan yeşil çalışanlar oluşturma eğilimindedir (Garcia vd., 2021). Bunu başarmak için, aynı zamanda yeşil ücret yönetimi gerçekleştirilerek, çalışanların motivasyonunu ve istekliliğini arttırmak amaçlanmaktadır.

Sağlık personelinin, çalıştığı kuruma yaptığı katkı neticesinde aldığı ücret, o personelin çalışma hayatının ana gayesi olan gelir elde etme çabasının neticesi olarak değerlendirildiğinde, ücret yönetiminin sağlık çalışanı ve kurum için ne kadar önemli olduğu ortaya çıkmaktadır (Kavuncubaşı \& Yıldırım, 2018). Temel ücret yönetiminin yanında, sağlık personeline yeşil hedefler sunularak, hedeflere ulaşma durumlarına göre ekstra ücretlendirme politikaları uygulanabilir. 


\section{Sonuç ve Öneriler}

Yeşil IKY ve uygulamaları sadece çevresel duyarlılık ve küresel bir sorumluluk olarak görülmemeli, aynı zamanda sağlık kurumlarının ana hizmeti olan sağlığın geliştirilmesi ve toplumsal yansımasının iyileştirilmesi olarak da ele alınmalıdır.

Mousa ve Othman, (2019), Yeşil insan kaynakları yönetimi uygulamalarının sağlık kuruluşlarında sürdürülebilir performans üzerindeki etkisi adı çalışmalarında; Yeşil IKKY uygulamalarının sağlık kuruluşlarında, çalışanlar arasında orta düzeyde uygulandığını ortaya koymuşlardır. Aynı şekilde bulunan sonuç bazı üretim sektöründeki çalışmalar ile benzerlik göstermektedir. Orta seviyedeki uygulamanın olası nedeni olarak ise sağlık sektörünün ekonomik kâr yerine toplumun tüm kesimleri için yüksek kaliteli ve düşük maliyetli tıbbi hizmetler sunmayı amaçlayan bir hizmet sektörü olması belirtilmiştir. Bunun sonucu olarak; sağıık kuruluşlarının çevresel uygulamaları benimseme noktasında henüz tüm faydalardan yararlanmadığını söylemek doğru olacaktır. Yine belirtilen bu çalışmada, en etkili yeşil uygulamanın "yeşil işe alma" olduğu ve ardından "yeşil eğitim ve katılım" olduğu; en az etkili yeşil uygulamanın ise "yeşil performans yönetimi ve ücretlendirme" olduğu ortaya konmuştur (Mousa \& Othman, 2019).

Sağlık kurumlarında, nitelikli işgücü istihdamı ve bu işgücünün örgütsel bağlılı̆ı her geçen gün sorun teşkil etmeye devam etmektedir. Bu çerçevede, nitelikli personelin kurumlarında görevlerine devam edebilmeleri için farklı ve farklılaştııımış insan kaynakları yönetimi uygulamalarının önemi her zaman göz önünde bulundurulması gereken noktalardan birisidir. Sadece geleneksel iKY uygulamalarının yerine aynı zamanda yeşil ikY uygulamalarının hayata geçirilmesi ve tüm kurum tarafından benimsenmesi, personelin motivasyonunu yükselterek, örgütsel sürdürülebilirliği sağlamaya yardımcı olacaktır.

Sağlık işgücünün işe alım esnasından başlayarak yeşil duyarlılık ve çalışma hayatında da bu duyarlılığa göre hareket etmesinin sağlanması, insan kaynakları yönetiminin önemli bir başarısı olacaktır. Bu başarı kurumların olağanüstü durumlara da (salgın, afet vb.) uyumlaşmasını kolaylaştırabilecektir.

Sağlık kurumlarında uygulanacak yeşil eğitim programları, hedeflerine etkili bir şekilde ulaşmak için hem idari hem de mali kaynaklara ihtiyaç duyar. Sağık kuruluşlarının çevre, yeşil eğitimi ve katııı uygulamalarını pahalı olarak algılaması muhtemeldir; bu durum, örgütlerin tıp eğitimine odaklanmak yerine yeşil eğitim programlarına daha fazla yatırım yapmaları gerektiğini göstermektedir. Ayrıca yüksek düzeyde çevresel sürdürülebilirlik performansı ve çevresel etki göstergelerinin (örneğin, kullanılan doğal kaynaklar, tıbbi atıkların ayrılması, kirlilik seviyeleri) sağlık sektöründe çevresel sürdürülebilirliğin tesis edilmesine yönelik ilerleme sağlayabileceğini göstermektedir (Mousa \& Othman, 2019).

Günümüzde sağlık kurumları, özellikle Sağlık Bakanlığı tarafından belirlenen Sağlıkta Kalite Standartları ile çevreye duyarlılık ve hassasiyet yönünden incelenmekte ve değerlendirilmektedir. Bu çerçevede; atık yönetimi politikaları uygulanarak, çevre ve insan sağlığının korunması yönünde faaliyetler yapılmaktadır. Sağlık personeline de bu konularda gerekli eğitimler verilerek, çevre bilincinin oluşturulması amaçlanmaktadır (Sağlık Bakanlığı, 2020).

Sağlık kurumları, sundukları hizmetin çıktısı olarak topluma faydalı bir dışsal yarar da ortaya koymaktadırlar. Her sağlıklı bireyin sağlıklı toplum için katkısı yadsınamaz bir gerçektir. Çevresel duyarlııı ve faaliyet ekseninde hizmet sunulması da sağlık kuruluşlarının toplumsal imajı ve yararııı̆ı açısından son derece önemlidir.

\section{Kaynakça}

Ahmad, S. (2015). Green human resource management: policies and practices, Cogent Business \& Management, 2: 1030817, http://dx.doi.org/10.1080/23311975.2015.1030817

Al Kerdawy, M.M.A. (2019). The role of corporate support for employee volunteering in strengthening the impact of green human resource management practices on corporate social responsibility in the Egyptian firms, European Management Review, 16, 1079-1095

Amrutha, V.N., Geetha, S.N. (2020). A systematic review on green human resource management: Implications for social sustainability, Journal of Cleaner Production, 247, 119-131

Anwar, N., Mahmood, N.H.N., Yusliza, M.Y., Ramayah, T., Faezah, J.N., Khalid, W. (2020). Green human resource management for organisational citizenship behaviour towards the environment and environmental performance on a university campus, Journal of Cleaner Production, 256, 120401

Arulrajah, A.A., Opatha, H.H.D.N.P., Nawaratne, N.N.J. (2015). Green human resource management practices: A Review, Sri Lankan Journal of Human Resource Management, Vol.5, No.1

Bektaş, G. (2011). Sağlık kurumlarında insan kaynakları yönetimi, Sağlık Yönetimi (Editör: yıldırım Kaptanoğlu, A.), Beşir Kitapevi, İstanbul, S.216

Bingöl, D. (2014). İnsan Kaynakları Yönetimi, 9. Baskı, Beta Yayınevi, İstanbul. S.455

Cabral, C., Jabbour, C. J. C. (2019). Understanding the human side of green hospitality management, International Journal of Hospitality Management, https://doi.org/10.1016/i.ijhm.2019.102389

Demir Uslu, Y., Kedikli, E. (2017). Sürdürülebilirlik kapsamında yeşil insan kaynakları yönetimine genel bir bakış, Üçüncü Sektör Sosyal Ekonomi, 52 (3), 66-81

Deshwal, P. (2015). Green HRM: An organizational strategy of greening people, International Journal of Applied Research, 1(13): 176-181

Garcia, M.U., Cortes, E.C., Lajara, B.M., Saez, P.Z. (2021). Corporate social responsibility and firm performance in the hotel industry. The mediating role of green human resource management and environmental outcomes, Journal of Business Research, 123, 57-69

Jabbour, C. J. C., Jabbour, A., B., L., S. (2016). Green human resource management and green supply chain management: Linking two emerging agendas, Journal of Cleaner Production, 112, 1824-1833, http://dx.doi.org/10.1016/j.jclepro.2015.01.052

Jeronimo, H. M., Henriques, P. L., Lacerda, T. C., Silva, F. P., Vieira, P. R. (2020). Going green and sustainable: The influence of green HR practices on the organizational rationale for sustainability, Journal of Business Research, 112, 413-421

Kavuncubaşı, Ş., Yıldııı, S. (2018). Hastane ve sağlık kurumları yönetimi, Siyasal Kitapevi, Ankara, S.331-366

Korkmazyürek, Y. (2019). Sağık kurumlarında insan kaynakları yönetimi, Sağlık kurumları yönetimi (Editörler: Demirci, A. ve Manavgat, G.), Gazi Kitabevi, Ankara, S.102

Kumar, V. (2020). Organizational sustainability and green business practices - The way forward, Organizational sustainability and green business practices The way forward, Materials Today: Proceedings, https://doi.org/10.1016/j.matpr.2020.09.791

Millar, J. H., Sanyal, C., Camen, M. M. (2016). Green human resource management: a comparative qualitative case study of a United States, multinational corporation, The International Journal of Human Resource Management, 27:2, 192-211

Mishra, P. (2017). Green human resource management: A framework for sustainable organizational development in an emerging economy, International Journal of Organizational Analysis, 25-5, 762-788, https://doi.org/10.1108/IJOA-11-2016-1079

Mousa, S., K., Othman, M. (2019). The impact of green human resource management practices on sustainable performance in healthcare organisations: A conceptual framework, Journal of Cleaner Production, 243, https://doi.org/10.1016/j.jclepro.2019.118595

Oncer, A. Z. (2019). Örgütlerde yeşil insan kaynakları yönetimi uygulamaları: Teorik bir inceleme, i̧ş ve Insan Dergisi, Ekim 2019, 6 (2): 199-208

Pham, D. D. T., Paille, P. (2019). Green recruitment and selection: an insight into green patterns, International, Journal of Manpower, Emerald Publishing Limited, 0143-7720

Pinzone, M., Guerci, M., Lettieri, E., Redman, T. (2016). Progressing in the change journey towards sustainability in healthcare: the role of 'Green' HRM, Journal of Cleaner Production, 122, 201-211

Rawashdeh, A.M. (2018). The impact of green human resource management on organizational environmental performance in Jordanian health service organizations, Management Science Letters, 8 (2018) 1049-1058

Renwick, D.W., Redman, T., Maguire, S. (2013). Green human resource management: A review and research agenda. Int. J. Manag. Rev. 15 (1), 1-14.

Renwick, D., Redman, T., Maguire, S. (2008). Green HRM: A Review, process model, and research agenda, University of Sheffield Management School, Discussion Paper.

Sabuncuoğlu, Z. (2013). Uygulama örnekleriyle insan kaynakları yönetimi, 7. Baskı, Beta Yayınevi, İstanbul. S.78

Sağlık Bakanlığı, (2020). Sağglıkta kalite standartları, hastane, Sağlık Hizmetleri Genel Müdürlüğü, Sağlıkta Kalite, Akreditasyon ve Çalışan Hakları Dairesi Başkanlı̆̆ı, Ankara. S.451 
Singha, S.K., Giudice, N.D., Chierici, R., Graziano, D. (2020). Green innovation and environmental performance: The role of green transformational leadership and green human resource management, Technological Forecasting \& Social Change, 150, 119762

Siyambalapitiya, J., Zhang, X., Liu, X. (2018). Green human resource management: A proposed model in the context of Sri Lanka's tourism industry, Journal of Cleaner Production, 201, 542-555

Tang, G., Chen, Y., Jiang, Y., Paille, P., Jia, J. (2018). Green human resource management practices: Scale development and validity, Asia Pacific Journal of Human Resources, 56, 31-55

Vardarlier, P. (2016). Strategic approach to human resources management during crisis, 12th International Strategic Management Conference, ISMC 2016, 2830 October 2016, Antalya, Turkey, Procedia - Social and Behavioral Sciences, 235, $463-472$

Yavuz, N. (2020). Yeşil insan kaynakları yönetimi ve yeşil iş yetkinliklerinin içerik analizi yöntemi ile değerlendirilmesi, i̇şletme Araştırmaları Dergisi, 12(3), 26692681, https://doi.org/10.20491/isarder.2020.1000

Yu, W., Chavez, R., Feng, M., Wong, C.Y., Fynes, B. (2020). Green human resource management and environmental cooperation: An ability-motivationopportunity and contingency perspective, International Journal of Production Economics, 219, 224-235, https://doi.org/10.1016/j.ijpe.2019.06.013

Zaid, A. A., Jaaron, A. A. M., Bon, A. T. (2018). The impact of green human resource management and green supply chain management practices on sustainable performance: An empirical study, Journal of Cleaner Production, 204, 965-979, https://doi.org/10.1016/j.jclepro.2018.09.062

Zennun Beyatlı, H. (2017). Hastane ve sağlık işletmeleri yönetimi, Nobel Akademik Yayıncılık, Ankara, S.29 